\title{
The impact of changes in the geological conditions of road bedrock layers while the road was in use
}

DOI 10.2478/otmcj-2019-0008

Received May 13, 2019; accepted September 27, 2019

\begin{abstract}
This article examines the effective road reconstruction technologies applied during construction processes to ensure the required final quality of construction work. The construction quality and especially the overall levelness of roads are influenced by several factors. These factors include high-quality implementation of road structural layers, including active zones, which can be adversely affected by the undisciplined application of technology, insufficient engineering and poor geological surveys. Suitable and effective reconstruction technology provides the required quality of construction work yet does not significantly extend construction time. The authors propose stabilisation using cement or lime during reconstruction. This stabilisation method is used if the structure of the bedrock layers is finely granular. The stabilisation process consists of excavating the unacceptable bedrock layer and mixing it with additives and water. A principally different bedrock stabilisation method consists of completely replacing it with a gravel layer, which is used when individual base layers are diverse and stabilisation using additives would not guarantee the required results, i.e. improved strength characteristics. In some cases, the existing base layers are not suitable for use as road base layers because of their characteristics, such as volumetric instability. For this reason, they must be replaced with more suitable materials. This topic is documented by a practical example.
\end{abstract}

Keywords: construction, road, technology, quality, reconstruction

\footnotetext{
*Corresponding author: Darja Kubečková, Faculty of Civil Engineering, Department of Construction, VSB - Technical University of Ostrava, L. Podéště 1875, 70833 Ostrava-Poruba, Czech Republic E-mail: darja.kubeckova@vsb.cz

Stanislav Smugala, Faculty of Civil Engineering, Department of Construction, VSB - Technical University of Ostrava, L. Podéště 1875, 70833 Ostrava-Poruba, Czech Republic

František Indra, SAFETY PRO s.r.o., Rudná 1117/30a, 70300 Ostrava, Vítkovice, Czech Republic
}

\section{Introduction}

Hardening and stabilising road base layers are not new procedures. Issues concerning roads date back as far as the Roman Empire when building good-quality roads for transporting people and materials were necessary because of the enormous size of the Imperium. The corresponding historical development is documented by Ebels et al. (2004). The hardening and stabilisation of road base layers according to these theories were based on incorporating larger and, later on, smaller stones into the road base layers, thus creating a compact layer. The next development stage in the first half of the nineteenth century saw the use of compacting rollers, which were initially pulled by horses. Later, steam or spark-ignition engines were used. The use of these engines eliminated the costly procedure that the compacting process undoubtedly represented until then. A technological improvement of the compacting process after World War II described by Kodikar et al. (2018) applied vibration rollers. The vibration rollers outperformed previous technical solutions. In the 1970s, new vibration rollers, such as intelligent compaction (IC), were introduced to the market, equipped with a highly accurate GPS, including an accelerometer. Vibration rollers equipped with IC technology also employ (when compacting asphalt materials) infra temperature sensors that monitor the surface temperature of the newly laid asphalt. IC technology allows the degree of material compaction in individual road base layers to be monitored and automatically adjusted according to the investor's requirements. During the compacting process, IC rollers can create colour-coded maps that display the number of rollers operating in a certain area. Publications by Briaud and Seo (2003) study the speed and degree of compaction of these types of rollers.

Underestimating of surveys in construction practices is an adverse factor that contributes to poor quality in construction work, and the occurrence of faults during the construction process or soon after the work has been commissioned. Faults such as these prolong construction time or result in warranty claims and, therefore, raise the overall construction investment costs. When an engineered 
section of road malfunctions or develops a fault, applying effective reconstruction technology that ensures the road's quality yet does not extend the construction schedule or prolongs it in only a very limited manner is a good practice.

In situ road experience shows that the application of effective reconstruction technologies is efficient provided that updated outputs from engineering, geological and hydrogeological surveys are available. This knowledge can be documented in examples of roads and highways and their malfunctions and faults in the form of significant deformation and surface unevenness occurring shortly after commissioning the road or highway.

\section{Field investigation}

After the road examined in this study had been commissioned, significant deformations occurred, manifesting as unevenness and cracks in the road's surface. These deformations forced the closure of the road, and the construction contractor was required to conduct surveys under warranty to determine the cause of the faults and propose appropriate reconstruction methods.

Two hypotheses (why the deformations occurred) were proposed during the first stage of the process of identifying the causes of the faults:

1. The deformations occurred as a result of water that flowed in a manner not specified in more detail beneath the road and then froze.

2. The deformations occurred as a result of swelling soils in the base layer of the road.
The initial documentation and investigation work used to determine the cause of deformations in the road included are as follows:

1. geological maps

2. engineering and geological surveys

3. hydrogeological surveys

4. in situ surface diagnostics

5. probing works

6. laboratory diagnostics

Water flowing into the road base layers and then freezing and causing the deformations were ruled out. This was verified from the available bedrock materials and probing work. For this reason, all subsequent diagnostic works focussed on the second hypothesis, i.e. possible base layer composition changes as a result of swelling soils. The original results of the engineering, geological and hydrogeological surveys were, therefore, checked and updated.

The technical implementation of road structural layers and their active zones is always based on the corresponding engineering, geological and hydrogeological surveys (Horáková, 2012) in compliance with CGS geological maps no. 19, 1968, 2243, 2019 (Project implementation documentation, 2009; see Figure 1).

\subsection{Geological surveys}

The bedrock was analysed several times to propose a technical solution for road surface reconstruction. The corresponding diagnostics and other probing and surveys were
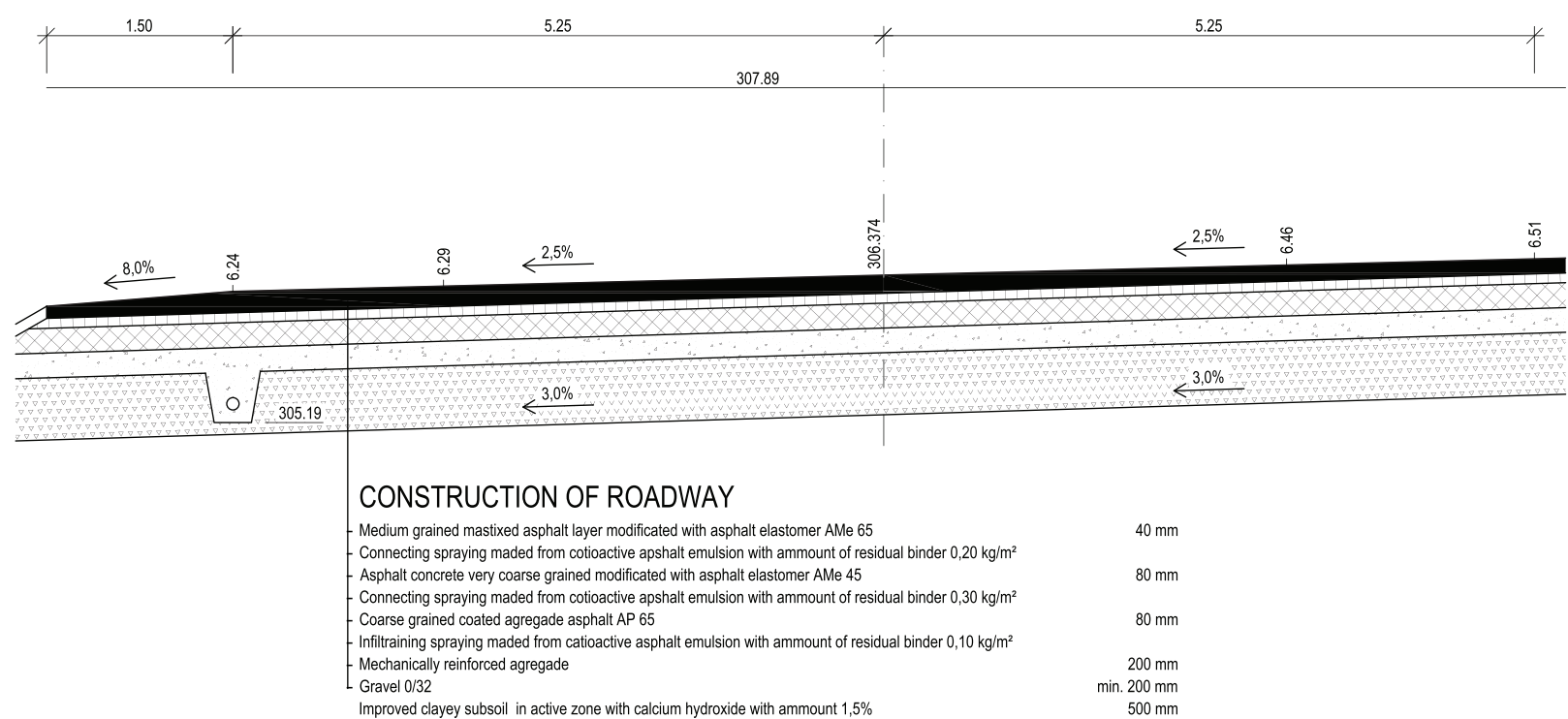

Fig. 1: Road cross-section with the original reconstruction measurements. 


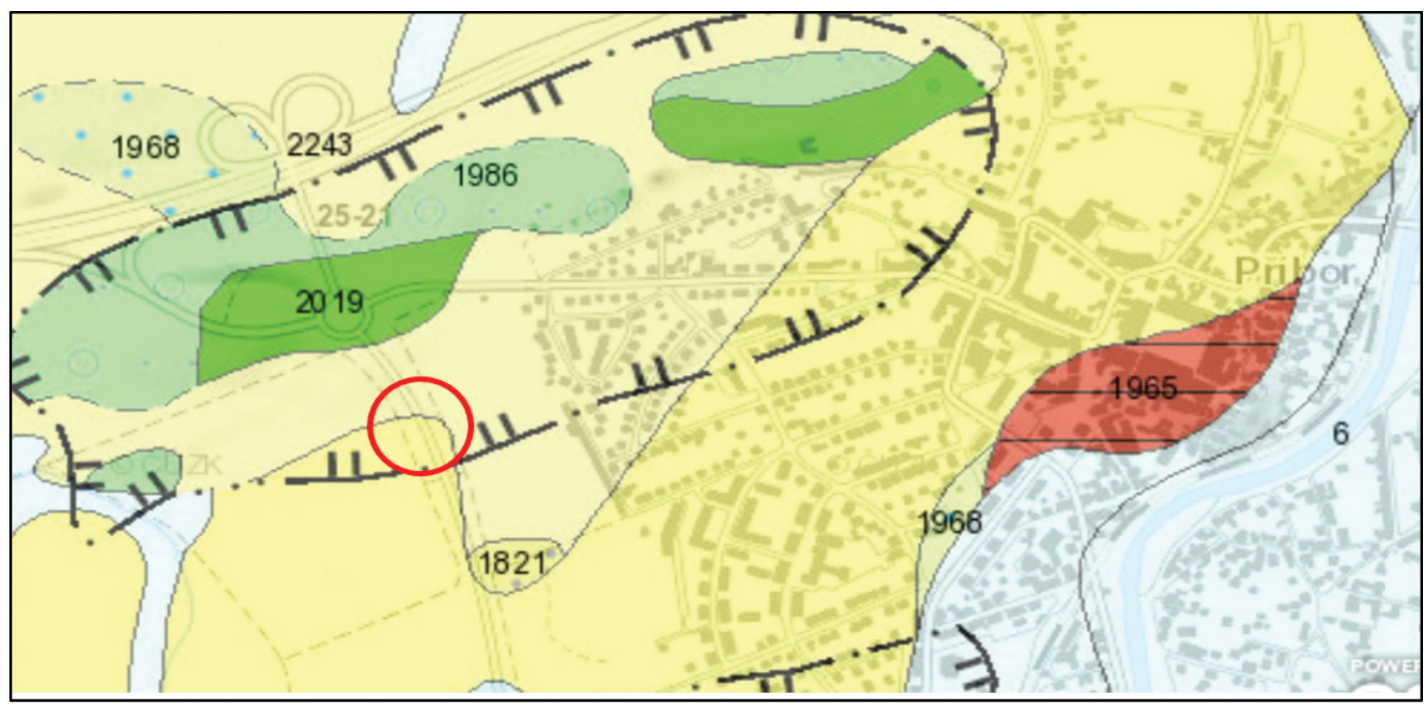

Fig. 2: Area according to the geological map [explanation of geological structures (the structures themselves relate only to the bold geological structure) is as follows: 19 light yellow-loess clay, genesis-eolic sediment, system-Bohemian Massif-covering formations, formation-quaternary, era-kenozoic, Pleistocene department; 2,243 ocher to pink-eluvial sediments (weathered mantle) stone-sand-clayey eluvia of sedimentary rocks, system-Carpathians, formation-quaternary to neogene, era-kenozoic, department Pleistocene; 1,821 ocher-yellow-marinated sediments, calcareous clay (tégl), in places with sand system-Carpathian Foredeep, formation-neogene, era-kenozoic, department-miocene, grade-Baden; 2,019 green-volcanites, cucumber, picrit, tuff, tuffite, system-Carpathians, area-flysch zone, region-outer group of nappes, regional unit-Silesian, formation-chalk, era-mesozoic, department-lower chalk, degree-berrias, Valangin, Hauteriv, Barrem, Apt, Formation-Volcanicities of the Ashtree Association; 1,986 bluish-marinated, sandstone, conglomerate, claystone, limestone, system-Carpathians, area-flysch zone, region-outer group of nappes, regional unit-Silesian, formation-chalk, era-mesozoic, department-lower chalk, degree-apt-alb, formation-Tešín-Hradiště; 1,968 grey-yellow with blue dots-marinated, claystone, sandstone, conglomerate, system-Carpathians, area-flysch zone, region-outer group of nappes, regional unit-Ždánice unit, sub-Silesian unit, formation-chalk to paleogene, era-mesozoic to kenozoic, department-Upper Cretaceous to Paleocene, degree-Turon, Coniak, Santon, Campan, Maastricht, Formation-Frýdek].

conducted in situ. Area for geological surveys and geological structures is shown in Figure 2.

\subsubsection{Sequence of activities}

1. Geology of the location

From a geological perspective, the road is located in a Carpathian Flysch Belt in the region of an outer group of nappes, the regional units of the Silesian, Ždanice and sub-Silesian regions.

Soil and rock here have different types and include vulcanite and marine sediments. The location has vulcanite of Těšín association, particularly represented by Těšín and picrite basalt, or diabase and its tufa and tuffite.

Another Mesozoic Era soil type is represented by marine sandstone, conglomerates, claystone and limestone of the Silesian unit Bosch development, formed by a Těšín and Hradištsko formation. It also contains Chlebovice layers, mostly formed by claystone with local shelves of Štramberk limestone. Similarly, the location also contains marine grey calcic claystone, sandstone and conglomerates of the Ždanice and sub-Silesian unit formed by the Frýdek formation. Map of the plan illustrates the geology clearly and the road that is the subject of the solution (see the red ring in Figure 2). The information obtained from the geological survey shows that the covered formations at the road's location are formed by eolic loess sediments and Quaternary sediments from the topsoil layers of the Chlebovice and Frýdek layers.

2. Surveys

The surveys included a macroscopic assessment of the rippled areas on the road's surface. The surrounding building structures and terrain were examined (notch slopes, surface drainage system, bridge structure supports, shoulder, etc.). Several survey probes were proposed at the affected locations of the road to determine the geological conditions at the location and the causes of deformation in the road. The surveys consisted of five engineering and geological boreholes with a depth of 2-4 m, two dynamic penetrations with a depth of $4 \mathrm{~m}$ and one excavated probe (dimensions of $1 \mathrm{~m} \times 4 \mathrm{~m}$ ) with a depth of $1.9 \mathrm{~m}$. The 


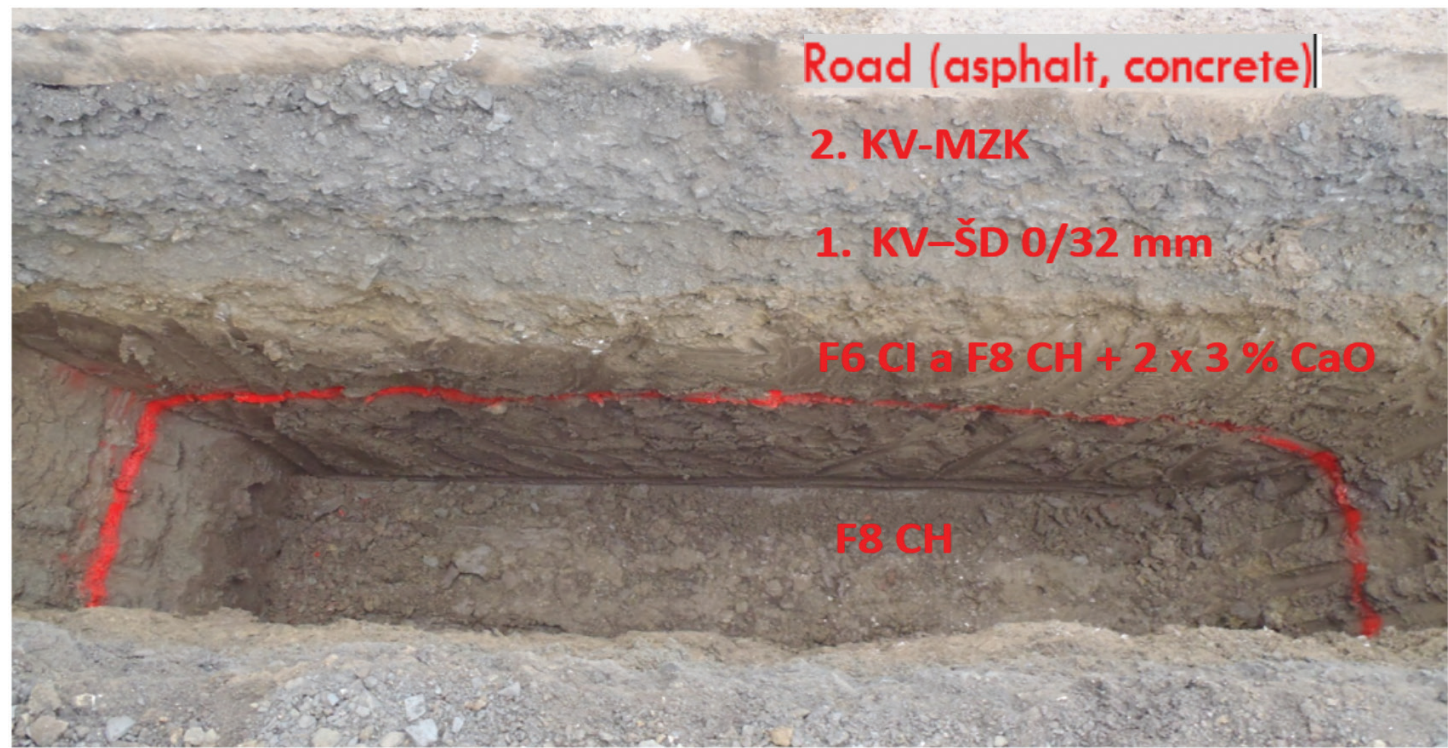

Fig. 3: Profile of the excavated survey probe showing the deformation of the underbase layer.

surveys included collected soil samples for laboratory analyses to determine natural moisture content, granularity, index characteristics, soil categorization, swelling capacity, Immediate load Bearing Index (IBI), California Bearing Ratio (CBR) and lime content.

The surveys revealed two road structural layers beneath the asphalt and asphalt-concrete road surface. These layers were 0.5-0.6 m deep, with the following composition (from top): second structural layer $=$ MZK, first structural layer $=$ ŠD fraction 0-32 mm.

Their base contained a lime-treated $(2 \times 3 \%$ $\mathrm{CaO}$ ) active zone (Figure 3). The bedrock consisted of eolic loess sediments of class F6 CI and eluvial, highly plastic claystone and siltstone with a class FB $\mathrm{CH}$ soil character. The depth of the treated soils was approximately $0.5 \mathrm{~m}$. The bedrock of the lime-treated soils included untreated eluvial claystone F8 $\mathrm{CH}$. The probes exposed volcanic Těšín basalts with a class $\mathrm{S} 4$ SM soil character.

Underground water was not detected by any of the conducted survey probes and agreed with the statement on the geological conditions. The probes discovered water penetration in the sediment, and considering the hypothesis, had a very high probability of being the primary cause of road deformation.

3. Water from bridge structure supports

The first assumption suggested that the key water penetration into the sediments and swelling occurred as a result of rainwater flooding in the excavated construction pits of the bridge and signalling post foundations during construction. During the construction process, the bridge structure contractor excavated soil from the construction pits and subsequently left them open for a longer period than originally planned (probably even for several months) because of technical problems related to bypassing electrical lines.

These problems meant that the construction pit was left exposed for a long time to any precipitation that occurred, which flowed into the pit and remained there because the surrounding clay soils and eroded clays were practically impermeable. This situation caused pools of water to form at the construction site.

The pools may have subsequently fed water to the surrounding sediments, which were prone to swelling. The project's documentation indicates that the depth of these pools would have been approximately $3 \mathrm{~m}$. The natural moisture of claystone at greater depths of 2-4 $\mathrm{m}$ below the road surface was (in five of the six cases) $w_{n}=16.49-18.86 \%$. In considering the very low claystone (eluvial clays) permeability of $k_{f}=1.58-1.81 \times 10^{-9}\left(\mathrm{~m} \mathrm{~s}^{-1}\right)$, the swelling process (upon coming into contact with water, the soil experienced swelling for 3-4 days, after which the process ceased) and the character and locations of the largest road deformations, the geotechnician did not believe this hypothesis probable.

4. Rainwater penetrating the active zone

Another hypothesis suggests that the key sediment-water absorption and swelling (untreated by any hydraulic bonding agent) occurred especially throughout the active zone treated with lime, which 
at the time of assessment showed a very high natural moisture content in the range $w_{n}=31.21-51.25 \%$, which is a very high value for lime-treated soils. The moisture content of lime-treated soils should normally be around $15-20 \%$. The results of the tests conducted at the assessed section of the structure immediately after modifications showed that the natural moisture content of the treated soil was less than $20 \%$. Its moisture content value, therefore, must have increased after modification. However, the cause of excessive moisture volume in the active zone during this stage of the study could not be determined.

5. Rainwater from the drainage trenches

The available information and study of the corresponding documentation showed that the water could not have reached the active zone from the surface drainage trenches. The trenches were built along both sides of the road and drained surface water from the notched slopes. Penetration of the drained water into the road structural layers and, therefore, into the road's active zone was improbable, as the water would have flowed through the drainage trench from the problematic section of the structure's surface along the path of least resistance. Furthermore, surface drainage was implemented in layers of eluvial clay, which are almost impermeable.

6. Rainwater penetrating the road shoulder

Yet another potential source of high moisture content in the active zone may have been rainwater that penetrated the sufficiently permeable road structural layers on the shoulder (gravel made from a crushed road surface/recycled asphalt material). Water may have flowed along the surface of the ground and subsequently penetrated the entire active zone. The construction contractor did not support this hypothesis, however, the contractor was convinced that all water penetrating the shoulder would be led away via the deep drainage system, which was located along both edges of the road and whose bottom was approximately at the same level as the sub-base layer. The functionality of the drainage system was verified as a part of the surveys.

7. Underground water from the FRANKI posts Another water source affecting the problematic locations could have been water flowing in from the FRANKI posts on which the adjoining bridge structure supports were built. This assumption was again contradicted by the relatively low natural moisture content of less than $20 \%$ in the claystone at greater depths. The excavated probe set up just a few meters from the bridge structure did not record any incoming water that would penetrate the main locations of deformation from the above-mentioned structure or notch slope.

8. Underground water permeating from the volcanic Těšín sediment layers

The final possible water source was water penetrating the active zone in the northern part of the structure through the body of the eroded Těšín sediments, which have clayish sand (S4 SM) character and are located at the structure immediately below the road active zone. Considering their permeability of $k_{f}=1.94 \times 10^{-6}\left(\mathrm{~m} \mathrm{~s}^{-1}\right)$, they could have been a water source for the active zone under certain circumstances. Nevertheless, it was not possible to confirm or rule out this hypothesis. At the time, the surveys were conducted and no underground water was detected in these eroded rocks. However, this did not conclusively mean that the rocks contained no water before or after the soils were treated with the bonding agent. Despite this, the geotechnician did not consider this situation probable.

9. Soil moisture issue in the active zone and bedrock The basic condition for determining the causes of the deformations in the road was moisture measurements at individual layers located below the road structural layers. These measurements were followed by a swelling test of the base layers.

Based on the unreasonably high moisture levels found in the treated soils in the active zone at all survey probes and on the relatively low moisture found in the claystone at a depth of less than $2 \mathrm{~m}$ below the road surface, the geotechnician recommended collecting additional soil samples from the level immediately below the underbase layer to determine the natural moisture content of the soil at the corresponding depth. The soils in question included soils treated with $\mathrm{CaO}$ from the ceiling and base of the active zone and untreated soils from the immediate base of the active zone. The values of the natural moisture content in the soil $\left(w_{n}=25.70-49.90 \%\right)$ are shown in Table 1.

The $w_{n}$ values suggest that the deformations in the road were caused by swelling of the claystone layer located in the immediate base of the active zone, i.e. at a depth of approximately 1.1-1.5 m below the road surface, and that this swelling was a result of high water content in the claystone after water penetrating from the very moist road active zone. Even so, the origin of the high moisture content in the treated soils in the active zone was not known at the time of the engineering and geological surveys were conducted. 
Tab. 1: Results of the analysis of natural moisture content in the soil

\begin{tabular}{lllll}
\hline Probe & Depth $(\mathrm{m})$ & $\begin{array}{c}\text { Moisture } \\
\text { content, } \\
\boldsymbol{w}_{n}(\%)\end{array}$ & $\begin{array}{l}\text { CaO } \\
\text { treat- } \\
\text { ment }\end{array}$ & Level \\
\hline KS1 & $0.6-0.8$ & 31.41 & Yes & Active zone, ceiling \\
& $0.8-0.9$ & 49.90 & Yes & Active zone, middle \\
& $0.9-1.1$ & 45.70 & Yes & Active zone, base \\
& $1.1-1.2$ & 25.70 & No & Base, ceiling \\
\hline
\end{tabular}

\subsection{Water saturation of soil in the active zone and bedrock}

Several possible water sources that may have been the cause of the swelling in the active zone layers were considered. Soil swelling analyses were conducted on 14 collected samples. Their results showed the coefficient values of the volumetric and respective linear swelling $B(\%)$. The soil swelling test was conducted in accordance with ČSN 666635 (1984) to determine the swelling and absorption values. The test measured increases in one or multiple dimensions of the tested sediments with shortterm moisture increases over time until the volumetric changes caused by swelling of the tested material had stabilized. The tested sediments did not cause any external strain during the analysis.

Monitored with an oedometer, the tested sediments were flooded with water. Height increases were subsequently observed using a deviation indicator. The height increases in these types of test were monitored after $1 \mathrm{~min}$, $10 \mathrm{~min}, 30 \mathrm{~min}, 1 \mathrm{~h}, 3 \mathrm{~h}, 8 \mathrm{~h}, 24 \mathrm{~h}$ and, if applicable, after more than 1 day. The test was considered complete when the difference between two subsequent readings is less than 0.005 ( $\mathrm{mm} /$ day). The test simulated clay (eroded claystone) behaviour after coming into contact with water. Generally, the stated soils have low moisture content but begin to absorb large amounts of water upon coming into contact with it, thereby creating the conditions for the development of swelling tensions. The test provided indicative information about the content and nature of clay minerals contained in the tested soils. Minerals of a montmorillonite character absorb water not only on their particle surfaces but also inside their crystals, which is why the highest swelling values can be recorded in materials containing a proportion of these clay minerals.

From the perspective of the swelling ratio [value of the volumetric swelling coefficient $B(\%)$ ], the laboratory tests confirmed that the problematic soils were not the soils treated with the $\mathrm{CaO}$ hydraulic bonding agent. The treated soils showed swelling values of $B=0.2-0.8 \%$, indicating that they were essentially not subject to swelling. The

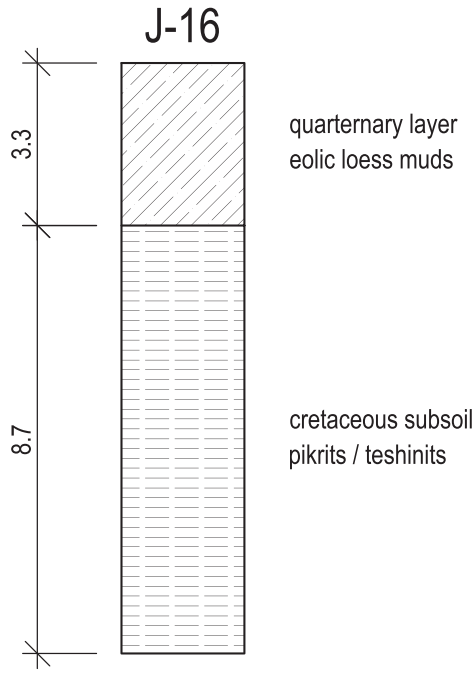

Fig. 4: Diagram of a geological borehole at the location of deformations.

soils in the road structural zones (MZK and ŠD fractions 0-32 mm) and the eluvia of the Těšín sediments (S4 SM) were not prone to swelling either.

From these results, it is clear that the volumetric soil changes causing deformations in the road were bound to the layer of the eluvial clays (eroded claystone) of the Frýdek and Chlebovice layers (grey, calcic highly plastic clays of class $\mathrm{F} 8 \mathrm{CH}$ ), which swelled relatively highly upon coming into contact with water $(B=2.5-12.3 \%)$. The swelling ratio of this claystone is quite variable, particularly due to the distinct content of clayish materials that are very susceptible to volumetric changes. The excavated probe confirmed that the main surface deformation problem was the result of swelling of the eluvial clays (eroded claystone).

\subsection{Bedrock stated in the original project implementation documentation}

Several geological boreholes were excavated along the given road section. The borehole designated J 16 penetrated the road where the deformations occurred when the road had been in use (Figure 4). Fine-granular soils at the construction site were initially treated using burnt lime [calcium oxide (CaO)], which was mixed with the soil using a ground cutter.

Soil treated with a bonding agent immediately changes its behaviour as a result of chemical reactions. Its natural moisture content is reduced, its load-bearing capacity is increased and its plasticity is altered. When clay minerals react with lime, a cation exchange takes 
place in which free $\mathrm{Ca}^{2+}$ ions replace sodium $\left(\mathrm{Na}^{+}\right)$and potassium $\left(\mathrm{K}^{+}\right)$ions in the crystalline structure.

Described in technical literature by Rogers and Glendinning (1996), Agashua and Ogbiye (2018) and Akinje (2015), the structure of the resulting material during this process changes from a stratified structure, which is typical for clay minerals, to a granular structure, which enables flocculation and agglomeration. The final product is no longer pliable and forms a rather granular (chunky) material.

Over the long term, the gel formed as a result of the reaction between lime and clay materials gradually crystallises until a solid and tight substance is formed. Hydroxyl ions $\left(\mathrm{OH}^{-}\right)$released from the reaction with lime create an environment with a $\mathrm{pH}$ that permits dissolution of $\mathrm{SiO}_{2}$ and $\mathrm{Al}_{2} \mathrm{O}_{3}$ from clay materials as well as a pozzolan reaction. The $\mathrm{SiO}_{2}$ and $\mathrm{Al}_{2} \mathrm{O}_{3}$ in the clay minerals react with water and lime. During this process, calcium, silicon and aluminium hydrate gels are formed. These gels gradually crystallise and connect individual structures. The result of this reaction, which is the subject of TP 94 (2013), is a tight material that is firmer than the original soil. Some of the immediate effects of treating soil with lime include drying, greater plasticity limits, greater firmness, IBI, CBR and less susceptibility to frost. During the soil drying process, burnt lime is hydrated according to the reaction $\mathrm{CaO}+\mathrm{H}_{2} \mathrm{O}>\mathrm{Ca}(\mathrm{OH})_{2}+65\left(\mathrm{~kJ} \mathrm{~mol}^{-1}\right)$ and some of the water evaporates as a result of heat generated by the exothermic reaction. Adding dry matter (lime) reduces the ratio between the weight of the water and the solid particles. Other effects of treating soil with lime include a pozzolan reaction (which is a long-term process in which gels crystallise and the soil and lime structures fuse together). The treatment process also results in greater permeability of the treated layer by one to two levels. We assume that the ISI soil values in the road active zone after soil treatment at the construction site were in accordance with the requirements of TP 94 (2013), soil treatment - technical conditions minimum $10 \%$.

The IBI results were compared with the soils in the active zone after approximately 6 months when their value was in the range of $6-10 \%$ and confirmed that the soil had completely lost the originally improved firmness parameters it had acquired immediately after being treated with lime in the space of several months. This probably occurred because of contact between the lime-treated soil and water (as a result of suction, i.e. water penetrating from the highly permeable layers of the eroded limestone). As a result of this process, the soil had become less firm, essentially untreated soil, more pliable and highly susceptible to frost. The expected long-term increases in the CBR load bearing values did not occur, the pozzolan reaction was interrupted and gel crystallization in the lime and soil mixture gradually stopped because of saturation. These processes resulted in no firm and tight material being formed.

The very low proportion of $\mathrm{CaO}(7.02-9.75 \%)$ in the lime-treated soils in the active zone (depth of 0.5-1.0 m below the road surface) discovered by laboratory analyses after 6 months was also problematic. Untreated bedrock eluvial clays (eroded claystone) at a depth of $2-4 \mathrm{~m}$ below the road surface showed the $\mathrm{CaO}$ content to be in the range of 3.21-9.72\%. From this information, we can infer that the penetrating underground water from the bedrock (with a specific, but undetermined chemism) could have caused a chemical reaction with the lime in the soil structure and removed it from the treated soil. This hypothesis, however, is not further discussed in this study.

\section{Reconstruction measurements}

The reconstruction proposal includes several technical solutions that aim to remedy the situation. All construction technology activities must be carried out in high quality. The technical aspect (in accordance with construction legislation) and the economic adequacy aspect must be taken into account. This was confirmed in the final.

\subsection{Initial reconstruction proposal}

Despite the real cause of the high moisture content in the active zone soils not having been determined at this stage of the survey, we proceeded in accordance with the reconstruction measures in the geotechnician's report:

- The existing road and its structural layers must be removed along the entire problematic section, i.e. from the outer edge of all identified road surface deformations sufficiently far on both sides of the bridge structure.

- The active zone (to its full depth) and bedrock comprising the swelling limestone must be excavated to a depth of $0.5 \mathrm{~m}$, i.e. to an overall depth of $1.0 \mathrm{~m}$ below the base layer along the same section.

- The deficient material must be replaced with fine-grain soils (e.g. fine-grain, medium-pliable soils treated with lime) with a low permeability of $k_{f}=n \times 10^{-8}$ to $n \times 10^{-10} \mathrm{~m} \mathrm{~s}^{-1}$ and low-to-medium pliability to seal the road base layers against water influx that may adversely affect the active zone soils and immediate surroundings. This material, however, was not available at the 
construction site at the given time, which is why loess or diluvial clays (daub) from an external source were recommended instead of those in accordance with the report on the use of fine-grain soils.

- Highly pliable eluvial clays (claystone of the Frýdek layers), which were present in the bedrock of the active zone before reconstruction and susceptible to swelling and thereby causing the deformations in the road, were not recommended as a suitable soil replacement.

- Selected and laboratory analysed material from another location was recommended. After specifying a suitable treatment, the material must be delivered to the construction site untreated. The material must then be treated in at least in two layers that are $1.0 \mathrm{~m}$ deep after compacting. Alternatively, if it is easier for the contractor, the selected material can be treated with lime away from the section requiring reconstruction, then immediately transported, laid and sufficiently compacted. A detailed procedure of this step was included in the report on the use of fine-grain soils.

- The material's quality must be in accordance with ČSN 736133 (2010), on proposing and implementing ground structures. The material must be treated in accordance with TP 94 (2013). Material compaction and control tests must be conducted in accordance with ČSN 72 1006 (2015), on soil and stone compaction control.

- All road structural layers and asphalt surfaces must be executed on the treated underbase in accordance with the project documentation (with the corresponding gradient specified in the project documentation) with sufficient compaction and load-bearing capacity demonstrated using control tests. The control tests must demonstrate a suitable moisture level in the treated soil.

- No permeable material through which water could flow towards the bedrock limestone and thereby initiate volumetric changes was recommended for reconstructing the active zone and bedrock (because of the susceptibility of eroded claystone to swelling). According to these requirements, the contractor selected an impermeable material and submitted it for assessment. The material concerned was medium-pliable loess clay with a solid to firm consistency of class F6 CI (classified in accordance with ČSN 736133 (2010).

- Laboratory tests of the selected material demonstrated that the material was an almost impermeable, single-grain soil of class F6 CI, and medium-pliable clay $\left(w_{L}=40.6-44.4 \%\right)$ of a solid to firm consistency $\left(I_{c}=0.84-1.04\right)$ with a natural moisture content of $w_{n}=19.8-21.6 \%$ and was well treatable with lime. It was recommended for use in reconstruction of the active zone and bedrock of the rippling road in accordance with ČSN 736133 (2010) and the laboratory geomechanics protocol.

- The natural moisture content in the loess clay during the collection time fluctuated in the range $w_{n}=19.8-$ $21.6 \%$. The optimal moisture content determined in accordance with the Area Standard compacting ability test was $w_{\mathrm{opt}}=18.0 \%$. The difference between the two values was therefore negligible. Powder lime was recommended for treating the assessed soils along the problematic section of rippling road. The collected soil samples showed too low (unmeasurable) values in the immediate IBI without any added bonding agent, which is why the soil required treatment.

- The required IBI value of $10 \%$ was achieved in the soils with a natural moisture content of $w_{n}=w_{\text {opt }}+3 \%$ for a batch of $2.5 \%$ of $\mathrm{CaO}$. When less of the bonding agent was added, the IBI values were below $10 \%$, as required by ČSN 736133(2010). After adding the lime, the strength of the final mixture increased with time, demonstrated by the test results of the soil with bonding agents after 7 days of maturing and $96 \mathrm{~h}$ of saturation. The results of the laboratory tests confirmed that the best method of achieving the required CBR value greater than 15\% (bedrock PIII) and 30\% (bedrock PII) requirement for active zones in road bedrock in accordance with TP 94 (2013) and TP 170 (2010), respectively, was to use soils with a moisture content value of $w=w_{\text {opt }}+3 \%$ treated with $2.5 \%$ of $\mathrm{CaO}$, as stated in the report on the use of fine-grain soils (Indra, 2012) and the Laboratory geomechanics protocol.

- Soil treatment using lime $(\mathrm{CaO})$ was conducted in accordance with the valid standards and regulations ČSN 736133 (2010) and TP 94 (2013).

Based on the assessment of the material, the results of the laboratory analyses and the assessment of all stated findings, loess clay was recommended for use in reconstructing the road active zone and bedrock at the road's problematic locations. The clays were required to be treated with $2.5 \%$ lime and to possess a natural moisture content before treatment of around $w_{n}=21 \%$, which is in accordance with the geotechnician's report.

\subsection{Change in the geological conditions discovered after the commencement of reconstruction}

The bedrock was excavated according to the reconstruction proposal. The geotechnician assessed the exposed 


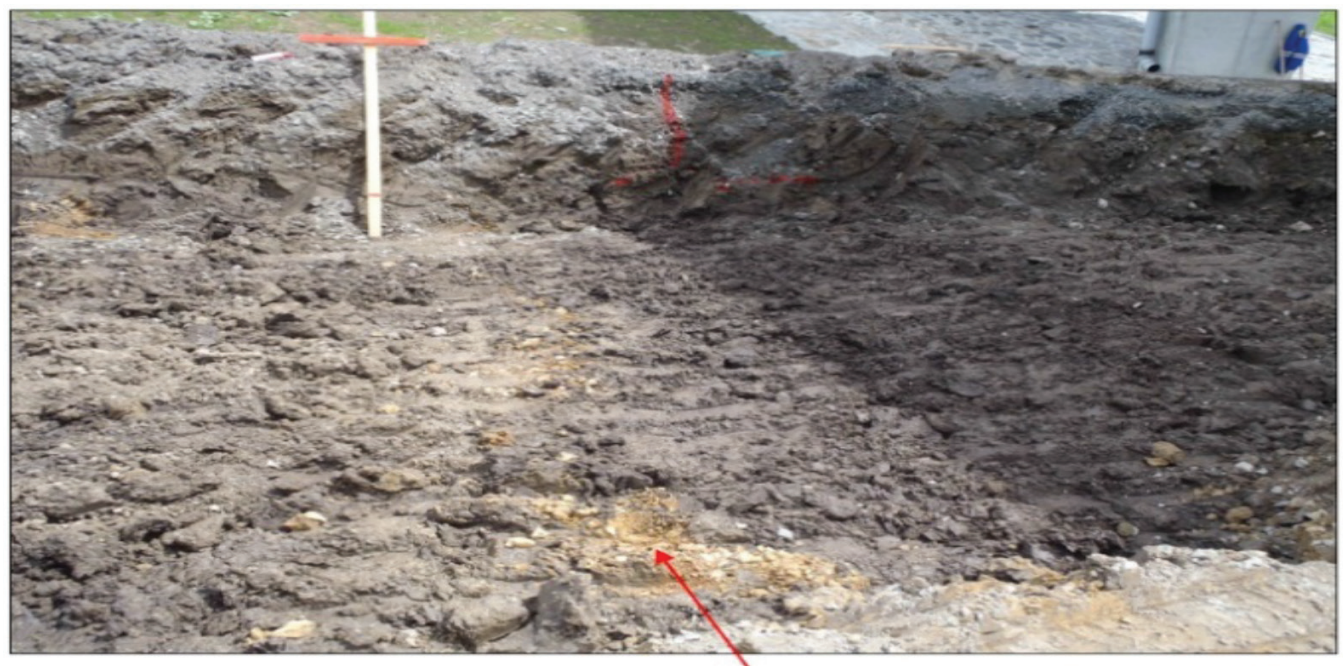

Fig. 5: Location of highly permeable rocks in the contact aureole in the active zone's bedrock.

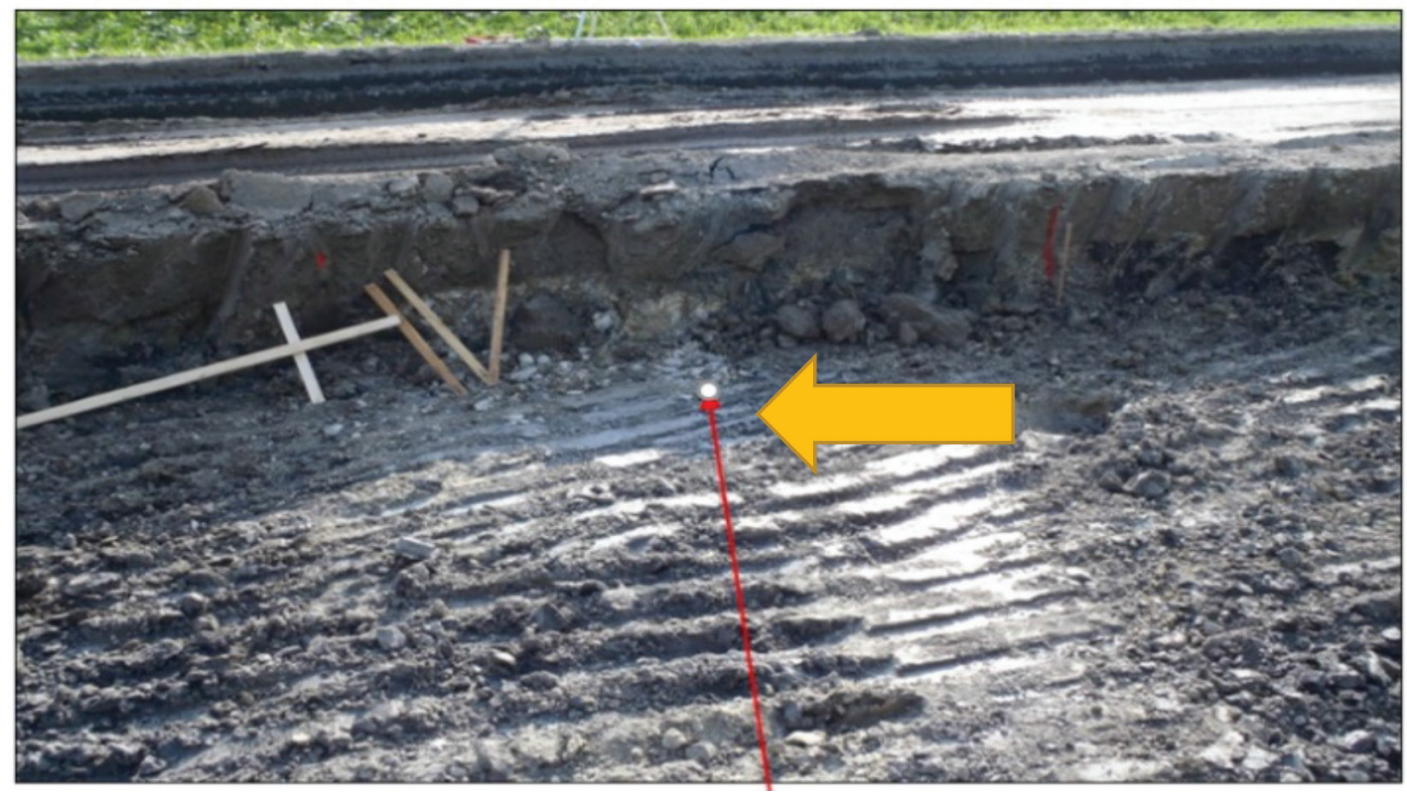

Fig. 6: Location of highly permeable rocks (limestone) in the active zone's bedrock.

bedrock of the problematic section of road. The original reconstruction proposal was based on the assumption of relatively homogenous bedrock; however, this assumption was proved premature after the given soil was excavated and the bedrock exposed.

The macroscopic assessment of the surface of the excavated bedrock identified significant inhomogeneity with permeating groundwater, due to which areas of eluvial clays (approximately $90-95 \%$ of the excavated soil) alternated with areas of highly permeable rock (Figures 5 and 6 ). The locally moist rocks were part of a contact aureole (Těšín sediments) with a shelf of marlite and limestone in the layer of eroded claystone. These rocks were not discovered by any of the survey probes, which is why their presence at the reconstructed section was unexpected. As moisture content increased, i.e. $w_{n}>20 \%$, which was very probable according to the conditions identified after removing the structural layers and active zone, the mechanical and physical characteristics of the treated bedrock could be changed. For this reason, the proposed reconstruction process was modified according to the proposal included in the reconstruction method modifications. 


\subsection{Theoretical solutions and principle}

As work is conducted, the reinforced bedrock characteristics may alter according to the degree of water saturation and result in, for example, pliable deformations or swelling of the base layers, which causes them to compress and thereby deform the top road layer. This problem is examined by several international authors, e.g. Tatsuoka and Gomes Correia (2018) and Tatsuoka (2015). Exploration of the volumetric changes in base layers according to their saturation is the subject of publications by Suriol et al. (2002) and Gould et al. (2011). Exploration of the characteristics of the bedrock layers during the process of compaction is the subject of theoretical work by Hogentogler (1936) and Holtz and Gibbs (1956). Their work describes individual stages in the development of bedrock layer characteristics. The relationship between the dry density of the bedrock $\gamma_{d}$ (or an empty ratio $e$ ) and the moisture content of the given bedrock $(w)$ has been defined by the Proctor compaction curve $h$ since the 1930s. Its basic principles were published by Proctor (1933). The CBR tests [CBR, which form a part of Australian standard AS 1289.6.1.1 (2014)] and the American ASTM standard (2002) are also used to define this relationship. The relationship is given by the typical compaction curve of a reverse parabolic shape in a plane, which defines the maximum density in dry conditions and corresponding optimal moisture content, e.g. in accordance with Australian standard AS 1289.5.1.1 (2017).

The issue of swelling claystone bedrock and tension formed as a result of volumetric changes are addressed in several publications (Alonso et al., 1999; Holtz and Gibbs, 1956; Kodikara, 2012). The initial bedrock moisture content at the time of compaction plays an important role in cases of increased bedrock volume as work is conducted. These increases can lead to deformations in the road surface layer. It has been demonstrated that the higher levels of bedrock moisture during the compaction stage do not later result in any deformation tensions if the bedrock is compacted with low pressure. This phenomenon was studied by Lawton et al. (1989). Unlike saturated bedrock, compacted clay bedrock with a low moisture content represents, as work is conducted and when the moisture increases or decreases, a change in the behaviour of individual bedrock layers that results in deformation of the structure. Bedrock may also be exposed to pliable deformation because of the dry/wet cycle (Figure 7) and subsequently achieve stable conditions. These stable conditions can be disturbed by floods, extended flows, or as in this case study, changes in the geological conditions.

Several numerical models have been created to describe these bedrock behavioural characteristics. They

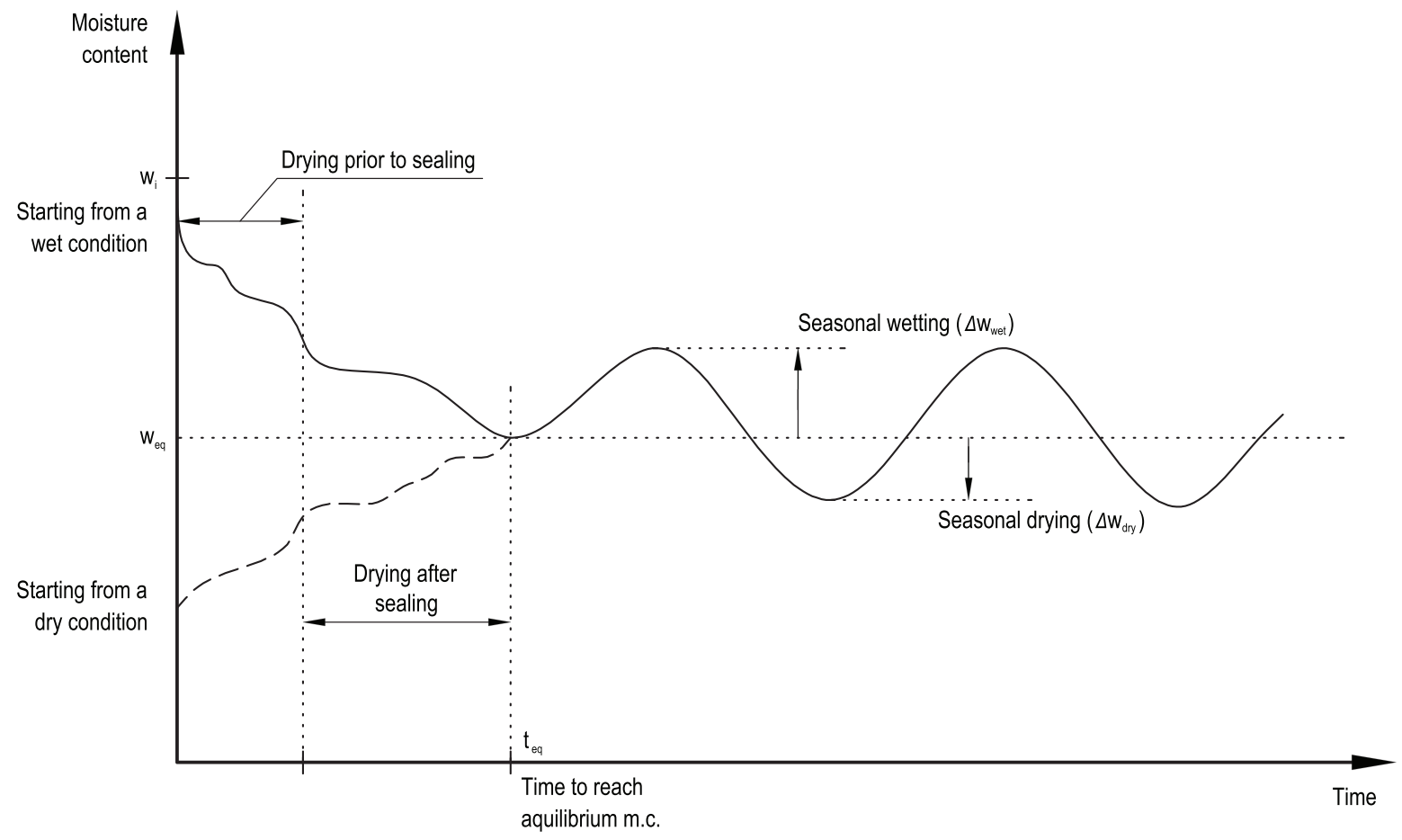

Fig. 7: Moisture content as work is conducted. 


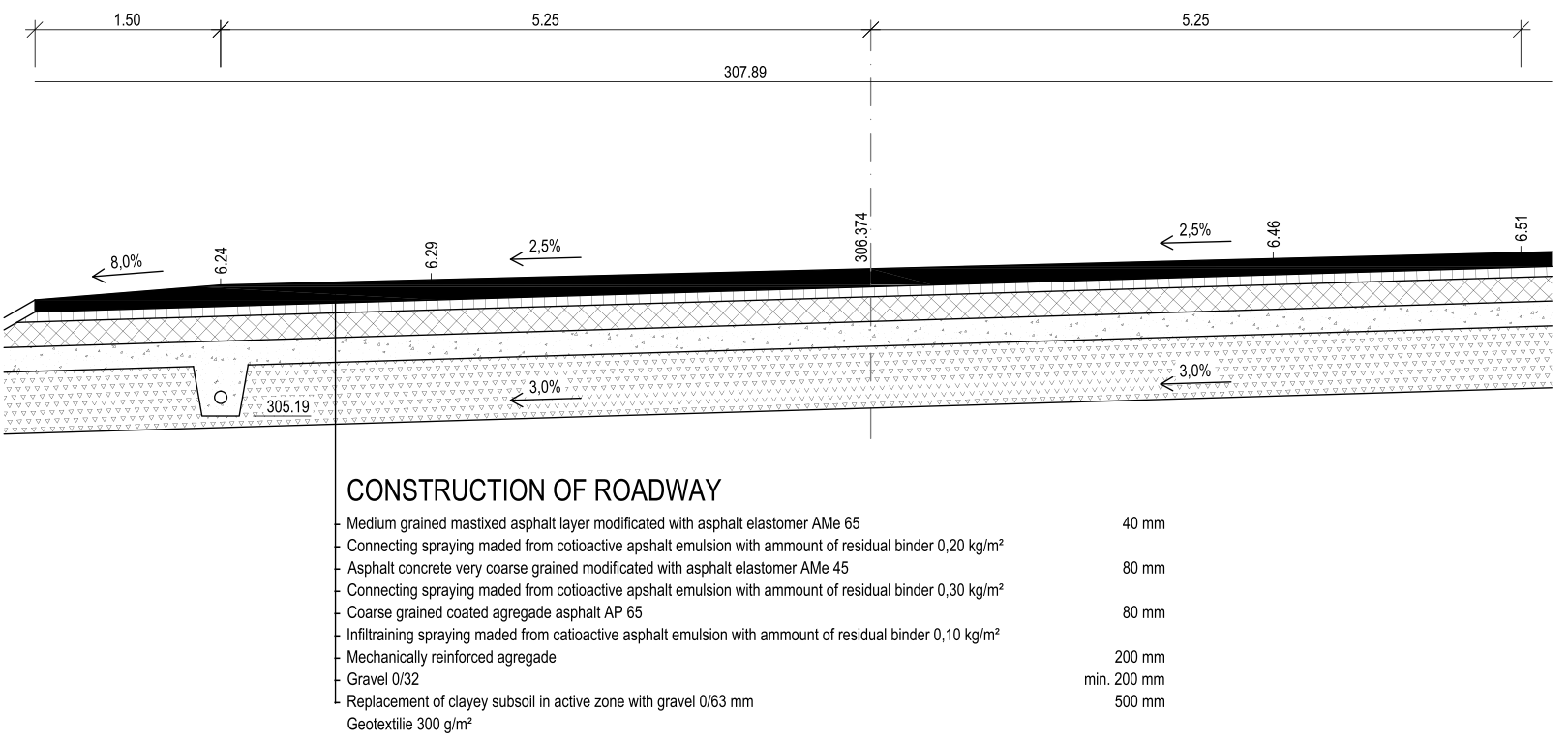

Fig. 8: Cross-section of the road according to the new reconstruction procedures.

include the Barcelona Basic Model, which is discussed in publications by Alonso et al. (1990) and others. The current constitutive modelling of the outer and environmental loads for unsaturated bedrocks is expressed in technical publications by Houlsby (1997) using the following equations:

$$
\begin{aligned}
& d W=-\sigma_{i j} d \varepsilon_{i j}-\frac{s}{(1+e)} d e_{w} \\
& d W=-\left(\sigma_{i j}+S_{r} s \delta_{i j}\right) d \varepsilon_{i j}-n s d S_{r}
\end{aligned}
$$

where $\sigma_{i j}$ is the net standard pressure, $d \varepsilon_{i j}$ is the tension tensor, $s$ is absorption power, $e$ is the ratio of cavities and $e_{w}$ is the moisture ratio. Based on Eq. (1), volumetric behaviour is expressed using the net pressure [with a volumetric pressure of $d e /(1+e)]$ as a conjugation, with a more exact absorption power of $s /(1+e)$ with $d e_{w}$ as a conjugation.

Two real situations may occur. In the first situation, partial saturation and loading take place, followed by the swelling process. In the second situation, bedrock layers are fully saturated as a result of flooding or changes in the geological conditions (as described in the case in this paper), allowing volumetric deformations of the bedrock layers to occur and thereby damage the top surface of the road, provided that the bedrock layers comprised reactive materials such as claystone. Based on the theoretical and observable knowledge mentioned above, the reconstruction procedure was modified.

\subsection{Modification of the reconstruction procedure}

In relation to the survey results mentioned above, which are exclusive to the problematic location, the occurrence of permeable rocks and permeating underground water flowing to the bedrock at the reconstructed area through local, isolated and randomly occurring fissure structures could not be considered in the original reconstruction proposal procedures. Based on the altered geological conditions discovered at the location after excavating the reconstructed layers, the geotechnician prepared new reconstruction procedures (Figure 8):

- Installation of a filtration geotextile was recommended at the surface of the inhomogeneous bedrock described above with a gradient of 3\% at a depth of approximately $1 \mathrm{~m}$ below the level of the projected underbase in accordance with the Construction Geology of Geotechnika, a.s., TP 97 (2008), aiming to achieve the requirements of the geotextile filtration function $(090 \leq 0.1 \mathrm{~mm}$, where 090 is the apparent opening size).

- Two drainage layers were recommended for the geotextile, each being $0.2 \mathrm{~m}$ thick. The first layer consisting of crushed stone with a fraction of 11-22 or 4-16 mm, and the second layer consisting of crushed stone with a fraction of $0-32 \mathrm{~mm}$.

- Replacement of the remaining deficient material was also recommended up to the level of the projected underbase with a frost-resistant, sufficiently permeable and well compactable material such as crushed 
stone with a fraction of $0-63$ or $0-125 \mathrm{~mm}$. All material must be correctly compacted in accordance with ČSN 72 1006 (2015) on soil and stone compaction control.

- Each drainage layer must be compacted separately. The remaining material (crushed stone with a fraction of 0-63 or 0-125 mm) must be compacted using a suitable mechanism in two layers.

- The material should be well-drained using a drainage system at the base of the excavation throughout the reconstruction procedure.

- All road structural layers and asphalt surfaces must be executed on the underbase (with the corresponding gradient in accordance with the project documentation) with sufficient compaction and load bearing capacity demonstrated using control tests (using an SZZ slab for roads) and in accordance with the project documentation.

- Similarly, the corresponding parameters of individual structural layers along the reconstructed section of the structure must be demonstrated by means of control tests with satisfactory results.

\section{Conclusions}

This article examined the problem of deformations on the surface of a given road. It described the process of identifying the causes of these deformations, methods of surveys conducted to determine the geotechnical conditions and soil characteristics at the location and hypothesized the possible causes of water penetration in the soil in the active zone and bedrock. This article also included proposals for reconstruction work, which developed significantly as individual survey stages progressed and new information about the marginal conditions at the location was acquired. The situation in this study may occur even after a geological survey has been sufficiently conducted because water saturation of soil in the active zone and bedrock may change over time. This can then result in changes in the mechanical and physical characteristics of the bedrock layers, which in turn can lead to surface deformations on a road, as in this case study. The changes discovered in the geological conditions demanded a revision of the reconstruction procedure. This procedure required complete replacement of the bedrock layers with frost-resistant and well-compactable materials in accordance with the revised reconstruction procedure. Compared to the originally proposed stabilisation using lime TP 94 (2013), this reconstruction method represents a more reliable alternative solution under these conditions.
The road deformation problem described in this article was successfully solved through the creative technical collaboration between the construction contractor, the geotechnician and the laboratory and was demonstrated by the fact that no other road deformations have occurred since modifying the reconstruction procedure in accordance with Chapter 2.3.4.

\section{References}

Agashua, L. O., \& Ogbiye, A. S. (2018). Influence of cement, bitumen and lime on some lateritic soil samples as pavement material. IOP Conference Series: Materials Science and Engineering, 413(1), pp. 012012. doi: 10.1088/1757899X/413/1/012012.

Akinje, I. (2015). Comparison characterization of A-6(10) laterite soil stabilized with powermax cement and hydrated lime separately. International Journal of Engineering and Technology, 5(7), pp. 392-401.

Alonso, E. E., Gens, A., \& Josa, A. (1990). A constitutive model for partially saturated soils. Geotechnique, 40(3), pp. 405-430.

Alonso, E. E., Vaunat, J., \& Gens, A. (1999). Modelling the mechanical behavior of expansive clays. Engineering Geology, 54, 173-183.

AS 1289.5.1.1. (2017). Methods of testing soils for engineering purposes-Soil compaction and density tests-Determination of the dry density/moisture content relation of a soil using standard compactive effort. Australian Standards, Sydney, Australia.

AS 1289.6.1.1. (2014). Methods of testing soils for engineering purposes-Soil strength and consolidation testsDetermination of the California Bearing Ratio of a soil-Standard laboratory method for a remolded specimen. Australian Standards, Sydney, Australia.

ASTM. (2002). Standard test method for California Bearing Ratio (CBR) of laboratory-compacted soils. American Society for Testing and Materials, West Conshohocken.

Briaud, J. L., \& Seo, J. (2003). Intelligent compaction: Overview and research needs. Texas, USA: Texas A\&M University.

Construction Geology, Geotechnika, a.s., TP 97. (2008). Geosynthetics in road ground bodies. Ministry of Transportation, Roadways Department.

ČSN 66 6635. (1984). Determining swelling and absorption values. Proposing unified methodological procedures and instrumental equipment for geotechnical tests.

ČSN 72 1006. (2015). Soil and stone compaction control.

ČSN 73 6133. (2010). Proposing and implementing ground bodies.

Ebels, L. J., Lorio, R., \& van der Merwe, C. (2004). The importance of compaction from an historical perspective. In Proceedings of the 23rd Southern African Transport Conference (SATC 2004). Pretoria, South Africa.

Geological map ČGS no. 19.

Geological map ČGS no.1968.

Geological map ČGS no. 2019.

Geological map ČGS no. 2243. 
Gould, S. J. F., Kodikara, J., Rajeev, P., Zhao, X.-L., \& Burn, S. (2011). A void ratio-Water content-Net stress model for environmentally stabilized expansive soils. Canadian Geotechnical Journal, 48(6), 867-877. doi:10.1139/t10-108.

Hogentogler, C. (1936). Essentials of soil compaction. In Proceedings of the sixteenth annual meeting of the highway research board (pp. 309-316), Washington, DC, November 18-20, 1936.

Holtz, W. G., \& Gibbs, H. J. (1956). Engineering properties of expansive clays. Transactions of the American Society of Civil Engineers, 121(1), pp. 641-677.

Horáková, I. (2012). Final report IGP PŘíBOR - S0112 - ROAD I/58, UniGEO.

Houlsby, G. T. (1997). The work input to an unsaturated granular material. Géotechnique, 47(1), pp. 193-196. doi: 10.1680/ geot.1997.47.1.193.

Kodikara, J. K. (2012). New framework for volumetric constitutive behavior of compacted unsaturated soils. Canadian Geotechnical Journal, 49, pp. 1227-1243.

Kodikara, J. K., Islam, T., \& Sounthararajah, A. (2018). Review of soil compaction: History and recent developments. Transportation Geotechnics, 17, pp. 24-34,

Kresta, F., ARCADIS Geotechnika, a.s., TP 94 (2013). Soil Treatment, Technical Conditions, Ministry of Transportation, Roadways Department.
Lawton, E. C., Fragaszy, R. J., \& Hardcastle, J. H. (1989). Collapse of compacted clayey sand. Journal of Geotechnical Engineering, 115(9), pp. 1252-1267.

Proctor, R. (1933). Fundamental principles of soil compaction. Engineering News Record, 111(9), pp. 245-248.

Project Implementation Documentation. (2009). "Road I bypass".

Rogers, F., \& Glendinning, S. (1996). Deep Stabilization Using Lime, Technology and Engineering, Loughborough University Civil Building.

Suriol, J., Gens, A., \& Alonso, E. E. (2002). Volumetric behavior of a compacted soil upon wetting. In: Proceedings of the $3 \mathrm{rd}$ International Conference on Unsaturated Soils. Recife, Brasil, vol. 2, pp. 619-623.

Tatsuoka, F. (2015). Compaction characteristics and physical properties of compacted soil controlled by the degree of saturation. In: Keynote lecture, deformation characteristics of geomaterials. Proceedings of the 6th International Conference on Deformation Characteristics of Geomaterials, Buenos Aires, pp. 40-78.

Tatsuoka, F., \& Gomes Correia, A. (2018). Importance of controlling the degree of saturation in soil compaction linked to soil structure design. Transportation Geotechnics. doi: 10.1016/j. trgeo.2018.06.004.

Varaus, M., Vébr, L., Zajíček, J., Fiedler, J., Amendment to TP 170. (2010). Proposing Road Structures, Technical Conditions. Ministry of Transportation, Roadways Department. 